\title{
Physical Modification of PLA for Increasing Its Durability (Polarizing Light Microscopy Study) ${ }^{\dagger}$
}

\author{
Beatrice Girbaciu ${ }^{1, *}$, Mariana Cristea ${ }^{2}$, Daniela Ionita ${ }^{2}$, Silvia Mathe ${ }^{3}$ and Doina Dimonie ${ }^{1}$ \\ 1 INCDCP-ICECHIM Bucharest, 202 Spl. Independentei, 6th sector, 060021 Bucharest, Romania; \\ ddimonie@yahoo.com \\ 2 "Petru Poni" Institute of Macromolecular Chemistry, 41A Grigore Ghica Voda Alley, 700487 Iasi, Romania; \\ mcristea@icmpp.ro (M.C.); d.ionita@yahoo.com (D.I.) \\ 3 Doctoral School "Applied Chemistry and Materials Science", University POLITEHNICA of Bucharest, \\ 313 Spl. Independentei, 060042 Bucharest, Romania; mathe.silvia@yahoo.com \\ * Correspondence: abgirbaciu@gmail.com \\ † Presented at the 15th International Symposium "Priorities of Chemistry for a Sustainable Development" \\ PRIOCHEM, Bucharest, Romania, 30 October-1 November 2019.
}

Published: 11 October 2019

Keywords: modified PLA; nucleation; reinforcing; morphology; order degree

The European Strategy for plastic materials in a circular economy underlines the importance of using renewable polymers for long-lasting applications. The purpose of the paper was to increase polylactic acid's (PLA) durability by controlling its crystalline structure [1-3].

The texture of the samples was analyzed in polarizing light with an Olympus BH-2 microscope, equipped with a THMS600 type heating system and a LINKAM TP92 temperature control system. The samples were studied during a heating/cooling cycle performed at a rate of $5{ }^{\circ} \mathrm{C} / \mathrm{min}$. The ATR-FTIR spectra needed for the chemical structure analysis was performed on a PerkinElmerSpectrum 100 instrument. The mechanical analysis was performed in a dynamic regime, on a PerkinElmer Diamond DMA instrument.

In the cooling stage of the neat PLA, the gradual formation of birefringent geometric shapes, next to which spherulites appeared, were observed. At $90{ }^{\circ} \mathrm{C}$, fine birefringent texture was formed, similar in characteristics to those of semi-flexible or rigid polymers (Figure 1). PLA reinforced with nucleation agent presents birefringence at room temperature, indicating a highly ordered material. In the case of the polymer with nucleation and reinforcing agents, and because of their effects, a marked decrease in the mobility of the macromolecular chains was observed.

The investigations of morphological changes by FTIR analysis, optical microscopy, and mechanical properties in a dynamic regime prove the increase of the crystallization ability of the modified PLA due to the reinforcing agents. 


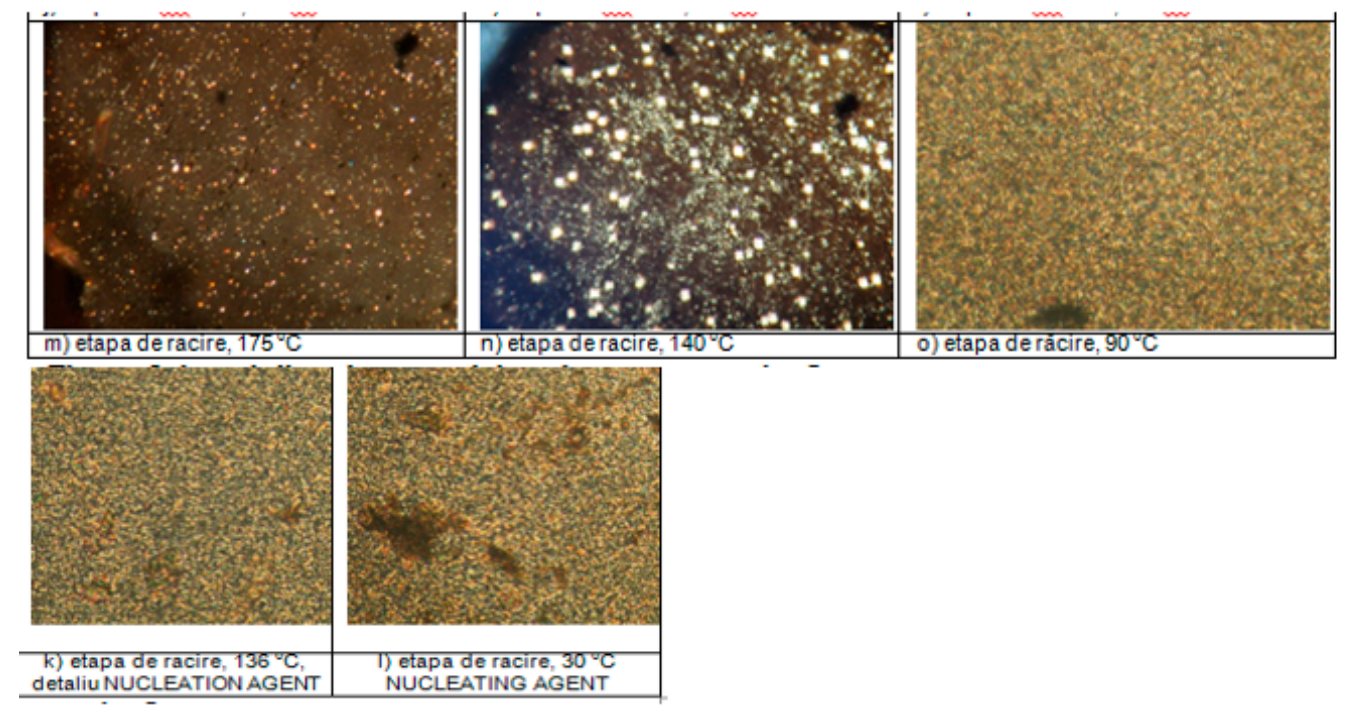

Figure 1. Polarized Light Microscopy (PLM) images of polylactic acid (PLA) without and with nucleation agent.

Acknowledgments: This work has been funded by the Ministry of Research and Innovation through project no. 40/2018-5/3D-LONG LIFE and 3PS/28.08.2019.

\section{References}

1. Benwood, C.; Anstey, A.; Andrzejewski, J.; Misra, M. Improving the Impact Strength and Heat Resistance of 3D Printed Models: Structure, Property, and Processing Correlationships during Fused Deposition Modeling (FDM) of Poly(Lactic Acid). ACS Omega 2018, 3, 4400-4411.

2. Pastorek, M.; Kovalcik, A. Effects of thermal annealing as polymer processing step on poly(lactic acid). Mater. Manuf. Process. 2018, 33, 1674-1680.

3. Smola, A.; Dobrzynski, P.; Cristea, M.; Kasperczyk, J.; Sobota, M.; Gebarowska, K.; Janeczek, H. Bioresorbable terpolymers based on 1-lactide, glycolide and trimethylene carbonate with shape memory behavior. Polym. Chem. 2014, 5, 2442-2542.

(C) 2019 by the authors. Licensee MDPI, Basel, Switzerland. This article is an open access article distributed under the terms and conditions of the Creative Commons Attribution (CC BY) license (http://creativecommons.org/licenses/by/4.0/). 